\author{
Błażej Osowski \\ Uniwersytet im. Adama Mickiewicza w Poznaniu \\ Instytut Filologii Polskiej \\ ORCID: 0000-0002-4226-1378; e-mail: blazej.osowski@amu.edu.pl
}

\title{
Wykładniki ekwiwalencji w wybranych inwentarzach z XVIII wieku
}

\begin{abstract}
Abstrakt: Artykuł przedstawia wykładniki ekwiwalencji, za pomocą których jest ona w tekście ustanawiana. Będziemy rozważać relację wewnątrzsystemową, w obrębie jednego języka, na boku pozostawiając ekwiwalencję w przekładzie. Ekwiwalencja to relacja semantyczna łącząca co najmniej dwa elementy (ekwiwalenty). Ekwiwalenty są równoważne w danym tekście, tj. mają wspólny referent (np. Jankesi $=$ Amerykanie), i mogą przyjmować formę pojedynczych wyrazów lub dłuższych fraz (np. Japonia $=$ Kraj Kwitnącej Wiśni). Ekwiwalencja może być przydatna dla dialektologa, ponieważ może służyć w tekście do zestawiania jednostek literackich i gwarowych. Wyróżniono środki składniowe, interpunkcyjne i leksykalne.
\end{abstract}

Słowa kluczowe: ekwiwalencja, relacje semantyczne, język polski, XVIII wiek.

\begin{abstract}
Exponents of equivalence in inventories from the 18th century. The article presents the exponents of equivalence by means of which equivalence is determined in a text. The intra-system relation (within a single language), disregarding equivalence in translation, has been considered. Equivalence is a semantic relationship that connects at least two elements (equivalents). The equivalents are corresponding in a text i.e. they have a common reference (e.g. Yankees =Americans), and may assume the form of single words or longer phrases (e.g. Japan $=$ The Land of Cherry Blossoms). Dialectologists can find equivalence useful as it can be applied in a text to juxtapose literary and dialectal units. Syntactic, punctuation and lexical means have been distinguished.
\end{abstract}

Keywords: equivalence, semantic relations, Polish, $18^{\text {th }}$ century.

Od wieku XIX trwa akcja naukowego dokumentowania gwar polskich; szczególnie intensywnie przebiegała ona w XX stuleciu. Stan gwar w epokach wcześniejszych jest nam dany jedynie pośrednio dzięki słownikom, świadectwom danego czasu (np. pamiętnikom, poradnikom, gramatykom) zawierającym uwagi o charakterze metajęzykowym, które wskazują na nacechowanie danego środka językowego (leksyki lub cechy gramatycznej), czy dzięki zabytkom językowym i stosowanym wobec nich przez badacza procedurom precypitacji (rzutowania w przeszłość cech współczesnych gwar) lub retardacji, tj. rzutowania cech gwarowych stwierdzonych dla przeszłości, np. dla wieku XVI, na czasy późniejsze, np. na wiek XVIII (Osowski 2016b, 101-102).

Jednym z niezwykle przydatnych źródeł do badania historycznej leksyki o ograniczonym zasięgu geograficznym (gwarowej i regionalnej) są inwentarze dóbr. Drobiazgowo zapisywano w nich stan majątku szlachty, króla, duchownych czy mieszczan, 
w tym powinności, stan posiadania oraz warunki życia chłopów - poddanych opisywanych dóbr. Uzyskujemy dzięki temu wgląd w życie dawnej wsi. Mimo że inwentarze należą do tekstów urzędowych, to jednak stanowią cenny materiał do badania słownictwa regionalnego oraz gwarowego, ponieważ pochodzą z jednego regionu, są określone pod względem czasu i miejsca powstania, nie są pisane w pełni polszczyzną literacką, stanowią replikę tekstu prymarnie mówionego (Kość 2004, 38-41; Osowski 2016b, 99-100).

Współwystępowanie w inwentarzach różnych odmian polszczyzny (literackiej, regionalnej, gwarowej, potocznej, specjalistycznej) skutkuje zjawiskiem wariantywności. Można zatem badać inwentarze pod kątem pojawiania się w nich cech gwarowych, jeśli sięgniemy po teksty z jednego tylko regionu, lub zastosować ujęcie porównawcze, jeżeli wykorzystamy inwentarze $\mathrm{z}$ różnych lokalizacji. Jest to możliwe, ponieważ dokumenty tego rodzaju były licznie spisywane w całej przedrozbiorowej Rzeczpospolitej. Można zatem założyć, że inwentarze wielkopolskie będą się różniły od mazowieckich, małopolskich itd. występującymi w nich cechami językowymi, a różnice te będą uwarunkowane - przynajmniej po części - geograficznie.

W niniejszej pracy sięgnięto po inwentarze pochodzące z różnych obszarów Rzeczpospolitej Obojga Narodów (Ch, K, Kob, KP, N, P, R, S, W), by przyjrzeć się na ich przykładzie ekwiwalencji. Należy pokreślić, że rozważana będzie ekwiwalencja jako relacja wewnątrzsystemowa, w obrębie jednego języka, natomiast nie będzie tu brana pod uwagę ekwiwalencja w przekładzie.

Do zjawiska tego odnosili się m.in. Roman Jakobson (1989, 373), John Lyons (1975, 492), Anna Wierzbicka (1971), Jurij D. Apresjan (1980, 318), Adam Bednarek (1989). Trzeba jednak zaznaczyć, że badacze nie są zgodni co do istoty czy zakresu ekwiwalencji. Część uwag na jej temat ma charakter fragmentaryczny - poczyniony na marginesie rozważań nad przekładem lub synonimią. Przyjmuję w artykule, że ekwiwalentami są dwa określenia pozostające ze sobą w następującej zależności: gdy używa się jednego, myśli się o obiekcie, o którym myślałoby się również, gdyby użyto drugiego (lub kolejnego) (Osowski 2016a, 308). Można, posługując się określeniem Wierzbickiej $(1971,112)$, stwierdzić, że ekwiwalenty łączy praktyczna równoważność. Ekwiwalenty mają wspólny referent, mogą przyjmować formę pojedynczych wyrazów lub dłuższych fraz (np. Japonia = Kraj Kwitnacej Wiśni), mogą tworzyć ciągi dłuższe niż dwuelementowe (np. Adam Mickiewicz = autor „Pana Tadeusza” = najwybitniejszy wieszcz romantyczny $=$ patron poznańskiego uniwersytetu $)^{1}$.

Ekwiwalencja jest zjawiskiem ciekawym dla dialektologa (badającego zarówno gwarę współczesną, jak i dawne jej przejawy), ponieważ może służyć w tekście do zestawiania jednostek z języka ogólnego i jego odmian geograficznych, np. spichlerz czyli sypanie. Oba określenia nazywają budynek lub pomieszczenie, w którym

${ }^{1}$ O ekwiwalencji jako izotopii zapewaniającej spójność tematyczną na poziomie lokalnym wspominali Bartmiński i Niebrzegowska-Bartmińska (2005, 274-277). Takie ujęcie zagadnienia jest jednak szersze od nas tu interesującego, ponieważ zdania typu Chłopiec przyszedl z kuferkiem. Kuferek położyl na ziemi czy Rozmawiali przeszło godzine, to była trudna rozmowa są przykładami par izotopicznych, tego rodzaju nie ekwiwalentów. Również niektóre środki kohezji i koherencji omawiane przez Wilkonia (2002, 72) w kontekście spójności tekstu pokrywają się z przykładami ekwiwalencji, jednak zasadniczo zbiory wykładników spójności i ekwiwalencji nie są tożsame. 
przechowywano ziarno; pierwsze należało w XVIII w. do polszczyzny ogólnej, drugie zaś - było wariantem śląsko-wielkopolskim.

W większości przypadków ekwiwalencja zostaje wprowadzona do tekstu po to, by maksymalnie ograniczyć presupozycję rozumianą jako wiedza niezwerbalizowana lub zwerbalizowana w niewielkim stopniu, wiedza, którą posiada zarówno nadawca, jak i odbiorca (Wilkoń 2002, 99). W sytuacji, kiedy nadawca tekstu (urzędnik, pisarz, kopista) oraz jego odbiorca (szlachcic) reprezentowali inny typ wykształcenia, erudycji i doświadczenia życiowego nie można było odwoływać się do zasobów wiedzy wspólnej; konieczne było przedstawianie obiektów i zjawisk jak najdokładniej. W tym celu sięgano po ekwiwalenty.

Celem artykułu jest określenie zbioru wykładników ekwiwalencji, za pomocą których w tekście jest ona ustanawiana. Adam Bednarek (1989, 14-15) rozróżnia leksykalne i interpunkcyjne wykładniki ekwiwalencji. Można je jednak jeszcze uzupełnić o środki składniowe. Od nich rozpoczniemy².

Ekwiwalencja realizowana składniowo łączy elementy na zasadzie postpozycji, np. Szarwark ręczna robota bez sprzężaju ${ }^{3}$ (Ch 23), JMP Kazimierza Sadowskiego szwagra mego prosze (K 4), W tej kaczmie mieszka Maciej $\boldsymbol{i}$ z żona oboje doroczni (KP 56), dnia 11 miesiąca kwietnia roku przeszłego 1788 ( $\mathrm{R}$ 5), w roku teraźniejszym 1765 (PM 151), Rok teraźnieyszy 1721 (S 220). Struktury tego typu są najprostsze spośród wszystkich tu omawianych. Można je uznać za pierwotny sposób wyrażania relacji ekwiwalencji, porównywalny z sytuacją, gdy nie znając obcego języka, przedstawiamy się: Ja Błażej. Ta najprostsza struktura może zostać rozwinięta za pomocą środków leksykalnych (Ja to Błażej; Ja jestem Błażej; Ja, czyli Błażej) lub przez zastosowanie rozwiązania konwencjonalnego, tj. znaków przestankowych ( Ja, Błażej; Ja - Błażej) lub innych graficznych $(J a=B ł a z ̇ e j)$, o czym szerzej w dalszej części tekstu.

Spośród znaków interpunkcyjnych najczęściej wykorzystywane są:

- przecinki, np. sortem Jmp. Zaliewskiego, miecznika Ziem Pruskich (Ch 33), Ten ja jestem, Antoni hrabia na Cieni Cieński, towczyc nadworny koronny (K 96), Katarzyna Ciesielska, Józefa Ciesielskiego żona (KP 141), po zejściu ostatniego dożywotniego posesora, niegdy $W$ Franciszka Stefana Lanckorońskiego, starosty raskiego (R 11); My niżej wyrażeni [...], przez konstytucyja sejmu konwokacyjnego a. 1764 postanowieni komisarze (PM 1);

- dwukropki, np. mensury cynowe: 1 funtowa, druga pólfuntowa (Ch 8), Holowników trzy: jeden do miodu, drugi do piwa, trzeci do hołowicy (N 246), owce inwentarskie jmp. Dobrzyckiego: maciorek starych 131, skopów cytaków 22, baranów 2, owieczek latosich 37, skopków 39, baranek 1 (KP 1);

- myślniki, np. W imię Przenajświętszej Trójcy - Boga Ojca, Syna i Ducha Świętego (K 24);

\footnotetext{
2 Zaproponowana klasyfikacja została opracowana na podstawie analizowanego materiału, nie ma więc charakteru zamkniętego czy skończonego. Przedstawiono typy wyraziste, jak zawsze jednak w tekście mogą zdarzyć się przypadki ich łączenia.

${ }^{3} \mathrm{~W}$ cytatach zaznaczam elementy połączone relacją ekwiwalencji przez pogrubienie, podkreślenie linią prostą i falistą.
} 
- kropki, np. Dwu jest mieszkańców. Pierwszy, Krystyjan Szlos [...]. Drugi, Andrzej Stefańczyk (PM 62);

- nawias, np. Hryc Żuk (kaleka) (Kob 37).

Najczęściej wykorzystywanym znakiem jest przecinek łączący elementy, których ekwiwalencja zasadza się na zestawianiu różnych perspektyw. Z kolei dwukropek używany jest dla zestawiania elementów stanowiących określenie zbioru i jego składników (por. klasyfikację technik ustanawiania ekwiwalencji w Osowski 2021). Pozostałe znaki, tj. myślniki, kropki i nawiasy, pojawiały się o wiele rzadziej w interesującej nas funkcji.

Jak wiadomo, zasady stosowania znaków interpunkcyjnych są konwencjonalne, dlatego $\mathrm{w}$ podobnych kontekstach możemy znaleźć różne znaki, por. schemat zbudowany na zasadzie 'określenie zbioru - wymienienie elementów zbioru' w cytatach: Chalupników 5, pirszy Jędrzej Kowalski, drugi Btażej, trzeci Walenty Watęska, czwarty Walek Marciniak, piaty Idzi (KP 15) vs. Gburzy szarwarkowi: Michat Czapa [...] Adam Tokarski [...] Michat Tradel [...] Michat Focht [...] (PM 22). Raz ekwiwalenty połączone zostały przecinkiem, raz dwukropkiem.

Grupa wykładników leksykalnych jest najbardziej rozbudowana i zróżnicowana. Wyodrębnić w niej można 3 podgrupy.

1. Spójniki:

- a, np. od Pana Boga a Stworzyciela (K 13), ten Piotr Ptaszyński, a wnuk mój (K 119);

- albo, np. skrzyń macznych albo koryt dwie (Ch 38), suspicyja albo podejźrenie (K 145), Tabella albo Summaryusz Klucza Stawkowskiego (S 335), cztery cubicula albo izdebki (N 20), Pacyfikat albo krzyż ze czter[e]ma koralami pozłacany (N 44), taksa jego [wołu - B.O.] albo szacunek tal. bitych 6 (KP 149), Pierzenia albo ścianek niemasz wokoło (W 12);

- alias, np. Lemon gburek alias Zacharek (Ch 139), Jedna ćwierć Ślusarzowa, alias Mihalowa (Kob 40), ksiegi alias biblioteke (K 46), w nim [spichlerzu B.O.] sąsieków alias przegrod siedem (S 171), na kuratarzyk alias chodzenie do kolegium (N 11), Ozd alias suszenie (KP 18), przesta ciosane alias ptot (W 67), Baszta alias wieża (PM 9);

- czyli, np. obserwując nieżyczliwego czlowieka czyli kłótnika (K 110), Chrzcieńcom, czyli których do chrztu świętego trzymatem (K 199), na wschodach czyli Stopniach (S 262), Tabella Intraty czyli Zysku (S 386), [opisanie - B.O.] bursy czyli konwiktu pauperum studiosorum nobilium (N 3), przeciwko szemborzy, czyli stajen (KP 6), [kościół - B.O.] jeden farny, czyli parafijalny (R 4); z jurysdykcyja, czyli moca sadzenia spraw miejskich (R 13), Niwa czyli grunt Bialikiewiczowski pod lasem (W 95);

- $\quad i$, np. dyspozycyja i ostatnia wola (K 116);

- jako, np. Walenty Wlocki regent kancelaryjej grodzkiej sandeckiej, jako przyjaciel podpisuję się przy tym będacy (K 9);

- jako to, np. Dokumenta zaś wszelkie, jako to kontrakty, skrypta, kwity, z wypłaconych prowizyi, tudzież regestra wybieranych prowentów (K 191-192), nie które wsie Klucza tegoiako to Iaworzno, Byczyná, Dabrowa, Dlugosyn, Porabka (S 343), Pótrolników jest 11 jako to Fracek Bartosczyk, Michat Kościelny, Jacek 
Urbaniak, Mikotaj Idziak, Tomek Gzik, Tomek Olejnik, Domin[ik] Szkudlarek, Fabijan Jarunczak, Cypryjan Bartosczyk, Feliks Łuczak, Jan Ignaczak (KP 53), Tymże na ordynaryja, jako to piwo, zboże, mięso, korzenie etc. (PM 78);

- lub, np. Trzyny zaś, lub zgoniny (Kob 61);

- (a) raczej, np. Skór odbiera krowich dwie, a raczej jedna krowia, druga jałowica (Kob 57);

- to jest, np. Fridrich stalmah ma sobie budować $w$ dwojakach pańskich i one budować, to jest naprawiać (Ch 138), grzad numero 24, to jest marchwi zagonów numero $11 \mathrm{l} 1 / 2$, pietruszki pół zagona, grochu tycznego grzad wielogrochu numero 12 (Kob 55), temu - to jest Janowi Rarowskiemu - z serca odpuszczam (K 8), na Osmiu zagrodach to iest na Cwierciach 16 (S 296), Ornat bogaty nowy nieskończony, to jest bez galonów $(\mathrm{N}$ 52), Oddaje się także czynsz do brania od Żydów piniężny, to jest łopatkowego zt 200, targowego zt 270 (KP 6), $z 3$ lat, to jest od r. 1785 do r. 1788 (R 7), dnia 12 grudnia, to jest we wtorek po święcie Narodzenia [s] Najświętszej Maryji Panny 1752 a. (R 238), świni sześcioro, to jest trzy wieprze, a trzy świnie samice (W 21), córka Tomasza Chemtowskiego, to jest Teresa Baczka (W 76), na dniu dzisiejszym, to jest $\underline{\text { dn. }}$. 6 maja (PM 1);

- vel, np. N. 4to Cubiculum v[el] piwnica (N 16).

Jak widać z powyższego zestawienia, najczęściej wykorzystywane bywają alias, czyli, jako to, to jest. Dwa pierwsze oraz to jest służą do łączenia elementów synonimicznych, zaś dwa ostatnie pojawiają się często przy wyliczeniach.

2. Czasowniki i ich formy pochodne:

- tworzące orzeczenie imienne z orzecznikiem rzeczownikowym (grupy nominalne użyte referencjalnie; Grzegorczykowa 2008, 32), np. Cialo moje, które jest masa zgnitości (K 51), stryj każdy jest drugi ojciec (K 210), Pryncypalne jej dobra jest wieś Regnow (R 40), Tej wsi jest posesorem emfiteutycznym ur. Wojciech Cielecki (R 211);

- czasowniki wskazujące na transformację obiektu, np. góra na śpichlerz obrócona (Ch 92);

- verba dicendi odnoszące się do nazywania, nadawania/używania nazwy, np. Podle pod zakrystia jest więzienie, które się zowie Księżna (Ch 121), Szopa trzecia śpichlerzem nazwana (Ch 156), do ojczyzny mojej, nazwanej Kukowice (K 17), ostatniej woli mojej (które powszechnie testamentem zowia) czynię rozporzadzenie (K 219), Trzecia szafa dluga, wąska, tymże malowaniem na zawiaskach z zamkiem, nazwana klucznica (N 22), Kazimierz, Utrzynos nazwany, z Biskupia poddany (KP 22), Miedzy rolami Mateusza Kujba i Marcina Bajona jest kawal roli, Naddawki nazwany (R 16);

- czasowniki wskazujące na mianowanie, nadanie komuś/czemuś jakiejś funkcji, np. Malżonke też moję jako najpierwsza opiekunke i szafarke dóbr zostawuje (K 4), za egzekutorów testamentu mego i opiekunów tak malżonki mojej, jak i dziatek upraszam i obieram, to jest: JMP Tomasza z Leśnej Leszczyńskiego ziemie sanockiej sędziego, WJMP Jana z Laskowej Jabłon Laskowskiego starosty cieszkowskiego, JMP Seweryna z Leśnej Leszczyńskiego, JMP Adama Mietkowskiego, JMP Wojciecha z Leśnej Leszczyńskiego (K 28). 


\section{Zaimki:}

- wskazujące, np. kwit Jaśnie Pana Ekonoma dla koni tegoż (Kob 130), Ażeby zaś ta moja dyspozycyja $i$ ostatnia wola nieodmieny $i$ niewzruszony odebrata skutek, za protektora onej upraszam [...] (K 116), Burs zielonego koloru /4 4/ Palec tegoż koloru / 4 (N 203), Monstrancja, w której postument miedziany pozłacany, sama zaś z promieniami i krzyżem srebrna pozłacana (N 253), stupów dla zgniłości onychże nowych potrzebujace [chlewy - B.O.] (KP 172), Maciek głuchy ma chałupe zła, pod cała przyciesi potrzeba inszych, komin i dach zły, stodoła takoważ (KP 229); moździerzyk z stluczkiem utraconym i sam u wierzchu odtluczony (W 23), przy nich furtka; ta na biegunach (PM 174);

- względne, np. Po prawey ręce Izba Gospodarska do ktorey drzwi na zawiasach z klamka drewniana (S 166).

W wymienionych przykładach zaimki zachowują się odmiennie od pozostałych wykładników, są bowiem nie tylko wykładnikami łączącymi ekwiwalenty, ale i nimi samymi. Frazę Iwan Kaliniak / Tenże czynszuje (Kob 35) uznać bowiem można za ściągnięte Tenże Iwan Kaliniak czynszuje, zaś Po prawej ręce izba gospodarska, do której drzwi na zawiasach pochodzi z przekształcenia dwóch zdań Po prawej ręce izba gospodarska. Do izby gospodarskiej drzwi na zawiasach. Po elizji grupy imiennej wywołanej czynnikami stylistycznymi jedynym śladem po niej jest zaimek, stając się tym samym wykładnikiem ekwiwalencji.

Inaczej funkcjonuje zaimek w przykładzie: Jan kowal, Kowalski zwany [...], z jona Magdalena $w$ lat 50 [...]. Ma ta kowalka brata Joachima w lat 16 na wędrówce (KP 102), ponieważ zaimek nie powtarza wprost treści wcześniej wprowadzonej w zdaniu.

4. Wykładniki operacji algebraicznych, tj. różne części mowy, które wyrażają relację równości pomiędzy wymienianymi wartościami:

- rzeczowniki, np. Świnie: zostawa świni starych 9, zostawa świnia roczna 1, zostawa wieprzów śtery rocznych, zostawa fus 1. - Suma sztuk 15 (Ch 43);

- czasowniki, np. W mace osepowa wchodzi: miar 12 dawnych, teraźniejszych miar 24 (Kob 42), Laska powinna być na sażni dwa i piadź chroma (Kob 78), a suma na posag wyżej wyrażona 30000 ztp., druga na wyprawę 8000 ztp., trzecia na klejnoty 4000 zlp., wraz złączona 42000 ztp. wynoszaca (K 134135), płacic powinni od Każdego Tramu fr: 2. od Tramow 9. czyni Zltb: 18 (S 377), pręt łokci 7 1/2 wynoszacy (KP 82)

- spójniki, np. Czynszowi wszyscy na Boże Narodzenie, Wielkanoc i Zielone Świątki drzewa zdatnego na budynek na każde święta po szt. 6, czyli ogólnie szt. 18, przywieźć powinni (KP 82), Lączka na Odpisku, z którego po 3 fury siana, fura jedna daje 10 cetnarów, zatem 30 cetnarów (W 109);

- zaimki, np. Ta wieś zasiadła na wlokach 9 [...], z których szoltyskich 2, gburskich 7 (PM 164).

${ }^{4}$ Ukośnik zastępuje w cytacie linie oddzielające poszczególne kolumny tabeli w tekście oryginalnym.

5 Tu też warto odnotować łacińskie dico używane dla ustanowienia relacji ekwiwalencji pomiędzy wartością wyrażoną słownie i liczbą - por. Krowa gniada, biało-biedrzasta, waloru złotych trzydzieści $\boldsymbol{i}$ trzy, dico zt[otych] 33 oddana (Kob 133), siedemdziesiąt i cztery tysiące dico 74000 ztp. (K 185), Item wotów para, które taxowane tynfów sześćdziesiąt dico numero 60 (W 72). 
Podsumowując, raz jeszcze należy powtórzyć, że przedstawione klasy wykładników ekwiwalencji zostały opracowane na podstawie analizowanego materiału. Tym samym wyodrębniony zbiór właściwy jest dla polszczyzny XVIII-wiecznej. Można zatem zakładać, że w innych okresach polszczyzna dysponowała innym zestawem środków. Potrzeba ustanawiania ekwiwalencji w tekście jawi się jako uniwersalna, a jednocześnie sposoby wprowadzania jej do wypowiedzi uzależnione są zarówno od czynników indywidualnych, jak i systemowych. Interesujące poznawczo wydaje się zatem ustalenie dynamiki zmian zjawiska. W tym właśnie należy widzieć perspektywę dalszych badań, tj. opracowanie zestawienia wykładników ekwiwalencji dla innych okresów rozwojowych polszczyzny z uwzględnieniem zróżnicowania stylistycznego (np. odmiana urzędowa vs. potoczna) i geograficznego (środki gwarowe, regionalne vs. ogólne). Do zbadania pozostaje również analiza stopnia wyspecjalizowania przedstawionych środków.

\section{Źródła}

Ch, Inwentarze dóbr biskupstwa chelmińskiego (1646 i 1676), wyd. R. Mienicki, Toruń 1955.

$\mathrm{K}$, Testamenty szlachty krakowskiej XVII-XVIII w. Wybór tekstów źródłowych z lat 1650-1799, oprac. A. Falniowska-Gradowska, Kraków 1997.

Kob, Inwentarze i rozliczenia folwarczne wsi Kobylnicy Ruskiej i Wołoskiej z lat 1711-1723, oprac. B. Kowal, S. Baran, Przemyśl 2014.

$\mathrm{KP}$, Materiały do dziejów chłopa wielkopolskiego $w$ drugiej połowie XVIII wieku, z ksiąg grodzkich wyboru dokonał i wydał J. Deresiewicz, t. 3: Województwo kaliskie, Wrocław 1957.

$\mathrm{N}$, Inwentarze kolegium jezuitów $w$ Nieświeżu oraz jego majątków ziemskich z przełomu roku 1773 i 1774, oprac. A. Mariani, Poznań 2020.

PM, Lustracja województw Prus Pomorskich 1765, t. 1: Województwo pomorskie, cz. 1: Powiaty pucki i mirachowski, wyd. J. Dygdała, Torun 2000.

R, Lustracja województwa rawskiego 1789, wyd. Z. Kędzierska, Wrocław 1971.

$\mathrm{S}$, Inwentarze $i$ lustracje klucza sławkowskiego z XVII $i$ XVIII wieku, do druku przygot. i wstępem opatrz. S. Witkowski i J. Krajniewski, Dąbrowa Górnicza 2013.

W, Inwentarze mieszczan wojnickich 1589-1822, wyd. B. Trelińska, Wojnicz 1995.

\section{Literatura}

Apresjan J.D. (1980), Semantyka leksykalna. Synonimiczne środki języka, przeł. Z. Kozłowska i A. Markowski, Wrocław.

Bartmiński J., Niebrzegowska-Bartmińska S. (2009), Tekstologia, Warszawa.

Bednarek A. (1989), Wykładniki leksykalne ekwiwalencji. Analiza semantyczna wyrażeń typu czyli, Toruń.

Grzegorczykowa R. (2008), Wyktady z polskiej sktadni, Warszawa.

Jakobson R. (1989), O językoznawczych aspektach przekładu, przeł. L. Pszczołowska, [w:] R. Jakobson, $W$ poszukiwaniu istoty języka, t. 1, wyb., red. i wstęp M.R. Mayenowa, Warszawa, s. 372-391. 
Kość J. (2004), Teksty ze sfery urzędowej w geolingwistyce diachronicznej, „Poznańskie Spotkania Językoznawcze", t. 13, red. Z. Krążyńska, Z. Zagórski, Poznań, s. 35-45.

Lyons J. (1975), Wstęp do językoznawstwa, Warszawa.

Osowski B. (2016a), Alias $i$ czyli jako przedmiot zainteresowania dialektologa historycznego, „Prace Filologiczne”, t. 68, s. 307-321.

Osowski B. (2016b), O jednym z XVIII-wiecznych źródet dialektologii historycznej z terenu Wielkopolski, [w:] Język $w$ regionie, region $w$ języku, t. 1, red. B. Osowski, J. Kobus, P. Michalska-Górecka, A. Piotrowska-Wojaczyk, Poznań, s. 93-108.

Osowski B. (2021), Techniki ustanawiania ekwiwalencji w wybranych XVIII-wiecznych inwentarzach dóbr szlacheckich, „Poznańskie Studia Polonistyczne. Seria Językoznawcza” (w druku).

Wierzbicka A. (1971), Metatekst w tekście, [w:] O spójności tekstu, red. M.R. Mayenowa, Wrocław, s. 105-121.

Wilkoń A. (2002), Spójność i struktura tekstu. Wstęp do lingwistyki tekstu, Kraków. 